\title{
Hydrodynamic Characterization of Phase Separation in Devices with Microfabricated Capillaries
}

\author{
Anand N. P. Radhakrishnan, ${ }^{\dagger}$ Marc Pradas, ${ }^{\dagger}$ Eva Sorensen, ${ }^{\dagger}$ Serafim Kalliadasis, ${ }^{\text {II }}$ \\ and Asterios Gavriilidis* ${ }^{* \dagger}$ \\ ${ }^{\dagger}$ Department of Chemical Engineering, University College London, Torrington Place, London WC1E 7JE, U.K. \\ ${ }^{*}$ School of Mathematics \& Statistics, Faculty of Science, Technology, Engineering \& Mathematics, The Open University, Walton \\ Hall, Milton Keynes MK7 6AA, U.K. \\ ${ }^{\text {II } D e p a r t m e n t ~ o f ~ C h e m i c a l ~ E n g i n e e r i n g, ~ I m p e r i a l ~ C o l l e g e ~ L o n d o n, ~ E x h i b i t i o n ~ R o a d, ~ L o n d o n ~ S W 7 ~ 2 A Z, ~ U . K . ~}$
}

\section{Supporting Information}

ABSTRACT: Capillary microseparators have been gaining interest in downstream unit operations, especially for pharmaceutical, space, and nuclear applications, offering efficient separation of two-phase flows. In this work, a detailed analysis of the dynamics of gas-liquid separation at the single meniscus level helped to formulate a model to map the operability region of microseparation devices. A water-nitrogen segmented flow was separated in a microfabricated silicon-glass device, with a main channel (width, $W=600 \mu \mathrm{m}$; height, $H=120 \mu \mathrm{m}$ ) leading into an array of 276 capillaries (100 $\mu \mathrm{m}$ long; width $=5 \mu \mathrm{m}$ facing the main channel and $25 \mu \mathrm{m}$ facing the liquid outlet), on

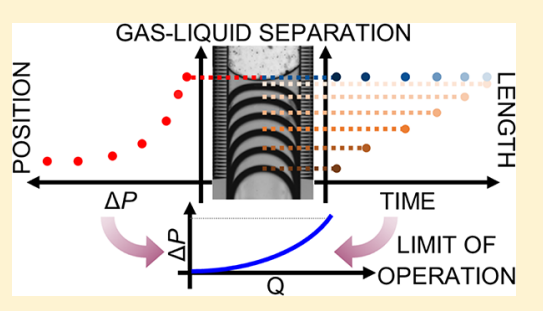
both sides of the channel. At optimal pressure differences, the wetting phase (water) flowed through the capillaries into the liquid outlet, whereas the nonwetting phase (nitrogen) flowed past the capillaries into the gas outlet. A high-speed imaging methodology aided by computational analysis was used to quantify the length of the liquid slugs and their positions in the separation zone. It was observed that during stable separation, the position of the leading edge of the liquid slugs (advancing meniscus), which became stationary in the separation zone, was dependent only on the outlet pressure difference. The trailing edge of the liquid slugs (receding meniscus) approached the advancing meniscus at a constant speed, thus leading to a linear decrease of the liquid slug length. Close to the liquid-to-gas breakthrough point, that is, when water exited through the gas outlet, the advancing meniscus was no longer stationary, and the slug lengths decreased exponentially. The rates of decrease of the liquid slug length during separation were accurately estimated by the model, and the calculated liquid-to-gas breakthrough pressures agreed with experimental measurements.

\section{INTRODUCTION}

Capillary-based separators are currently seeing a significant growth in their implementation for downstream separation of two-phase flows. Capillarity-driven separation can be exploited for their high efficiency and accurate spatiotemporal control afforded by advancements in microfluidics. ${ }^{1,2}$ Much of its application has been in microchemical reaction systems, ${ }^{3}$ where, for example, a gaseous component in a reaction requires a gas-liquid separation step to isolate the two phases. Such devices have also been applied for liquid-liquid extraction, ${ }^{4-10}$ gas-liquid separation in fuel cells, ${ }^{11}$ and safe handling of toxic or carcinogenic molecules. ${ }^{12}$ Capillarity-driven separators utilize either membranes or microfabricated capillaries to separate the phases. For membrane-based separators, ${ }^{13-16}$ it has been observed that factors such as membrane area, thickness, wettability, pore size, and tortuosity affect the separation process. Microfabricated separators ${ }^{17,18}$ achieve separation similarly by taking advantage of the differences in the wettability between the two phases and the surface tension of the liquid, with the added advantage that the pores are microengineered, hence having a uniform size, and are not tortuous. Although limited in their throughput, the fabrication of uniform capillary structures facilitates selective separation with controllable system behavior. For a typical hydrophilic substrate (e.g., silicon or glass), the wetted phase (e.g., water) flows through these capillaries, whereas the nonwetting dispersed phase (gas) is prevented from entering the capillaries due to the capillary pressure. ${ }^{19,20}$ Liquid-liquid separation can also be achieved through a similar methodology ${ }^{21}$ by taking advantage of the differences in the wetting properties of the two liquids.

The underlying phenomena of phase separation in capillary microseparators, at a scale where interfacial tension and capillary effects are dominant, are far from being fully understood. In terms of operational limits of capillary microseparators, the pressure at which the gas phase enters the capillaries (gas-to-liquid breakthrough), $\Delta P_{\mathrm{G}>\mathrm{L}}$, can be estimated from the Young-Laplace equation (appropriately modified for rectangular channels ${ }^{22}$ )

Received: December 18, 2018

Revised: May 15, 2019 


$$
\Delta P_{\mathrm{G}>\mathrm{L}}=P_{\mathrm{G}}-P_{\mathrm{L}}=2 \gamma \cos \theta_{\mathrm{e}}\left(\frac{1}{D}+\frac{1}{H}\right)
$$

where $\gamma$ is the surface tension, $D$ and $H$ are the capillary width and height (reflecting the principle radii of curvature of the meniscus), respectively, $\theta_{\mathrm{e}}$ is the equilibrium contact angle of the wetting liquid on a substrate, and $P_{\mathrm{G}}$ and $P_{\mathrm{L}}$ are the gas outlet and liquid outlet pressures, respectively. On the other hand, the liquid-to-gas breakthrough pressure, $\Delta P_{\mathrm{L}>\mathrm{G}}$, (i.e., the point at which complete liquid separation ceases and liquid exits through the gas outlet) is typically estimated from the pressure drop across the capillaries in the microseparator using the Hagen-Poiseuille equation. Several groups have reported deviations from these estimates for both gas-liquid and liquid-liquid separations. Various parameters were then included in the breakthrough models ${ }^{15,19,21,23,24}$ to account for (i) flow of liquid through $N$ capillaries in parallel, (ii) geometric correction factors (e.g., as described by Mortensen et al. $^{25}$ ), (iii) variations in apparent contact angles of the menisci, and (iv) the liquid slug lengths and number of active capillaries during separation. This modified equation is commonly given as

$$
\Delta \mathrm{P}_{\mathrm{L}>\mathrm{G}}=P_{\mathrm{G}}-P_{\mathrm{L}}=\frac{\alpha \eta L_{\mathrm{c}}}{N A_{\mathrm{c}}^{2}} \mathrm{Q}_{\mathrm{T}}
$$

where $Q_{T}$ is the total inlet flow rate assumed to be equal to $N Q_{c}$. Here, $Q_{c}$ is the flow through a single capillary, $\eta$ is the viscosity, $L_{c}$ is the length of the capillaries, $A_{c}$ is the crosssectional area of the capillaries, and $\alpha$ is a correction factor that is yet to be fully characterized.

To estimate the local flow rate through each capillary $\left(Q_{c}\right)$, knowledge of the pressure drop across them is required. This pressure drop is often estimated from the pressure difference between the local pressure at the entrance of a capillary and the liquid-side outlet pressure, assuming that all $N$ capillaries are used for separation (i.e., leading to $Q_{T}=N Q_{c}$ ). There is, however, enough experimental evidence suggesting that not all capillaries are used for separation. ${ }^{26}$ Furthermore, we are yet to understand and characterize the effect of capillary geometry, and hence, a geometric correction factor is still used in the Hagen-Poiseuille equation (e.g., $\alpha$ in eq 2). In the literature, only empirical equations exist to estimate the correction factor for rectangular or nonrectangular cross sections $s^{25,27}$ that are constant along the length of the capillary. However, in devices with nonparallel capillary walls, the cross-sectional geometry varies along the length of the capillary, thus affecting the local pressure drop, ${ }^{17,19}$ and such empirical correction factors can no longer be applied. Experimental investigation on such a capillary design could yield crucial information not only regarding the flow rate of the liquid through the HagenPoiseuille equation but also regarding the wetting properties in the capillaries and thus the gas-to-liquid breakthrough pressures. Experimental measurement of the contact angles in the capillaries is challenging due to limitations in optical imaging (i.e., imaging needs to be performed inside high aspect ratio capillaries with narrow widths and high depths, where the reflection of light is poor). Preliminary attempts with fluorescence microscopy were performed by our group to measure the velocity inside the capillaries. However, the presence of fluorophores in the liquid under investigation led to changes in surface tension, thus affecting the separation process. As regards the length of the liquid slugs in the segmented flow, which influences the separation process, ${ }^{19,21}$ investigations have been performed to either experimentally measure the slug lengths upstream of the capillary zone or estimate them from scaling laws (e.g., the model proposed by Garstecki et $\mathrm{al}^{28}$ ). However, the estimation from the scaling law by Garstecki et al. does not account for the dynamic variations in the liquid slug length during separation. This is because the formation of liquid slugs upstream of the capillaries is affected by the pressure variations due to the balancing of forces between the net inflow of liquid into the separation zone and the outflow of liquid through the capillaries. $^{23}$ Additionally, in gas-liquid separation, the variation in the gas bubble length due to the pressure drop across the two-phase flow in the inlet segment also leads to variations in the liquid slug lengths before entering the separation zone. All model estimations in the literature eventually result in a linear behavior of the liquid-to-gas breakthrough pressure $\left(\Delta P_{\mathrm{L}>\mathrm{G}}\right)$ with respect to liquid flow rate, where the complex hydrodynamics surrounding the two-phase flow remains unresolved.

In previous work, we experimentally investigated the effect of flow rates of a gas-liquid-segmented flow in a capillary microseparation device ${ }^{19}$ and also undertook a theoretical analysis of the breakthrough limits. In the present work, we advance the understanding of gas-liquid separation by developing a hydrodynamic model based on a liquid slug during separation in an array of microcapillaries. The development of the model is aided by in situ analysis of the liquid slug properties resolved by high-speed imaging, combined with a computational image analysis algorithm.

\section{EXPERIMENTAL SETUP}

Microfluidic Device Fabrication. Two gas-liquid separator designs, A-1 and A-2, with trapezoidal-shaped capillaries with a rectangular cross section (see Table S1 and Figure S1 in the Supporting Information for the design parameters) were fabricated on a 4 in. silicon $(\mathrm{Si})$ wafer (PI-KEM Limited, U.K.) via photolithography and deep reactive ion etching (DRIE) as described by Roydhouse et al. ${ }^{19}$ The silicon wafer was spin-coated with a positive photoresist (SPR-220-7, Rohm and Haas, USA) and soft-baked at 90 ${ }^{\circ} \mathrm{C}$ for $2 \mathrm{~min}$, followed by $115{ }^{\circ} \mathrm{C}$ for $3 \mathrm{~min}$. The separator pattern was transferred onto the photoresist using a UV mask aligner (Q40006, Quintel, USA). Pattern development was performed by immersing the wafer in a photoresist developer (MF-26A, Shipley Microposit, Dow Chemical Company, USA) for 2.5 min followed by thorough rinsing with deionized water. The wafer was placed at $115^{\circ} \mathrm{C}$ for 3 $\mathrm{min}$ as a post-exposure baking step. The device was then etched using a DRIE instrument (ICP DRIE, SPTS Technologies, U.K.) with a standard Bosch process. The depth of the etched devices was measured using a surface profiler (DektakXT, Bruker, U.K.). The wafer was diced into the desired dimensions using a precision dicing saw (DAD 3230, DISCO Corporation, Japan). A glass slide (Corning 7740, Newcastle Optical Engineering, U.K.), with predrilled holes for fluidic inlet and outlets, was anodically bonded to the $\mathrm{Si}$ wafer (400 ${ }^{\circ} \mathrm{C}$, $500 \mathrm{VDC}, 5 \mathrm{~min}$ ). Before bonding, the substrates were cleaned with acetone and deionized water (Millipore grade), followed by a final $\mathrm{O}_{2}$ plasma clean (Plasma Asher, Diener electronic, Germany) for $10 \mathrm{~min}$.

Gas-Liquid Separation Procedure. The separation performance was studied experimentally on a water-nitrogen system using the setup shown in Figure 1. Deionized water (Millipore grade, surface tension $=0.07 \mathrm{~N} / \mathrm{m}$, density $=1000 \mathrm{~kg} / \mathrm{m}^{3}$, viscosity $=8.9 \times$ $\left.10^{-4} \mathrm{~Pa} \cdot \mathrm{s}\right)$ was procured in-house and injected into a T-junction (internal diameter $=1 \mathrm{~mm}$, Upchurch Scientific, USA) using a displacement syringe pump (Legato 270P, KD Scientific, USA) at varying flow rates $\left(Q_{L}\right)$. Zero grade nitrogen (BOC, U.K.) was introduced via a mass flow controller (Bronkhorst, Netherlands), 


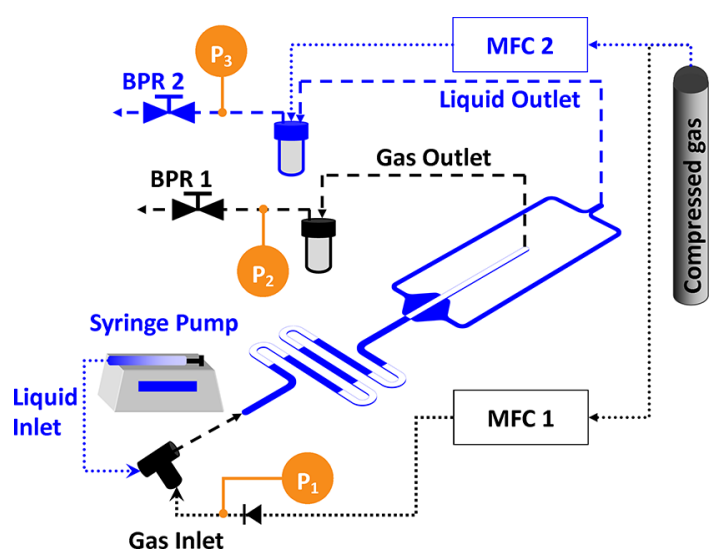

Figure 1. Schematic representation of the experimental setup. $\mathrm{P}_{1}-\mathrm{P}_{3}$ represent points of pressure monitoring. BPR: back pressure regulator; MFC: mass flow controller (image not to scale).

MFC 1 (in Figure 1), into the second port of the T-junction at a constant flow rate $Q_{\mathrm{G}}$ of $350 \mu \mathrm{L}_{\mathrm{n}} / \mathrm{min}$ to achieve a gas-liquidsegmented flow, which was introduced into the device. Pressures were recorded using $0-15$ psi pressure sensors (40PC015G Honeywell, U.K.), shown as $\mathrm{P}_{1}-\mathrm{P}_{3}$ in Figure 1, connected to a data acquisition board (USB-6000, National Instruments, U.K.) monitored via a script written on LabView 2015 (National Instruments, U.K.). The pressures at the gas and liquid outlets were controlled using adjustable back pressure regulators (KCB Series, Swagelok, U.K.) of ranges $0-10$ psi (BPR 1 in Figure 1 ) and $0-25$ psi (BPR 2 in Figure $1)$, respectively. The gas outlet was connected to a low-volume liquid collection vial ( $2 \mathrm{~mL}$ glass vial, Agilent Technologies, U.K.) before BPR 1 to trap any liquid exiting the gas outlet, especially during liquid-to-gas breakthrough case studies. Similarly, the liquid outlet was connected to a vessel (100 mL borosilicate glass, VWR International, U.K.) to collect the liquid exiting the device before BPR 2. The liquid collection vessel was pressurized by a separate nitrogen line at 20 $\mathrm{mL}_{\mathrm{n}} / \mathrm{min}$ controlled by MFC 2 .

The operating procedure followed to measure the breakthrough pressures is described in Figure S2 of the Supporting Information. The $\mathrm{P}_{2}$ pressure sensor recorded the gas outlet pressure $\left(P_{\mathrm{G}}\right)$, whereas the $\mathrm{P}_{3}$ sensor recorded the liquid outlet pressure $\left(P_{\mathrm{L}}\right)$. To establish successful separation, $P_{\mathrm{G}}$ was kept higher than $P_{\mathrm{L}}$, that is, the pressure difference $\Delta P_{\mathrm{GL}}$ was always positive. Considering a pure gas flow, the pressure drop from the last capillary at the gas outlet in the device to the pressure sensor was estimated to be around $4.2 \mathrm{~Pa}$ using the Hagen-Poiseuille equation, whereas the maximum pressure drop of water from the exit of the capillaries to the pressure monitoring point was around $302 \mathrm{~Pa}$.

High-Speed Imaging and Computational Image Analysis. The separation and breakthrough experiments were monitored using a high-speed camera (Mini AX100, Photron, USA) mounted on a microscope (Axioscope A1, Carl Zeiss, U.K.) with a vibration isolation platform (Newport Spectra-Physics, U.K.). Images were captured at 4000 frames/s for liquid flow rates $\left(Q_{L}\right)$ above $30 \mu \mathrm{L} / \mathrm{min}$ and at 1800 frames/s for $Q_{\mathrm{L}}$ below $30 \mu \mathrm{L} / \mathrm{min}$ at $10 \mu$ s exposure. The images (saved as TIFF) were processed offline. An automated image analysis script was developed in the Python programming language $e^{29-33}$ to measure the slug length and number of capillaries used by the liquid slug in the separation zone. Upon execution of the script, a sequence of images was opened, and they were then converted to a pixel array. The only manual intervention required from the user was to locate the walls of the main channel and the position of the first capillary on the images. The corresponding pixel coordinates were then used to measure the length scales in the images. To remove noise and small water droplets left on the top wall or the bottom of the separation zone, an image reconstruction step was adopted based on a morphological erosion filter (see Figure S3 of the Supporting Information). The reconstructed pixel arrays were then binarized to a Boolean array. Different contours in the binary images were estimated by an edge detection algorithm followed by a gradient filter. Only the contours touching both the edges of the walls were chosen as the menisci of the gas-liquid slugs, and the distance as well as the number of capillaries between them were measured (see Supplementary Movie 1).

\section{THEORETICAL FRAMEWORK}

A hydrodynamic theory for the calculation of the liquid-to-gas breakthrough pressure, $\Delta P_{\mathrm{L}>\mathrm{G}}$, calculation is developed next. We assume that the system is isothermal at room temperature and that the viscosities and densities of the liquid and gas phases remain constant during the experiment. We consider a liquid slug of initial length $\left(L_{0}\right)$ moving along the main channel of the microseparator at the superficial speed $U=Q_{\mathrm{T}} / A$, where $A$ is the cross-sectional area of the main channel and $Q_{T}=Q_{G}$ $+Q_{L}$ is the total flow rate that is the sum of the liquid and the gas flow rates. When the slug enters the separation zone (i.e., the array of capillaries), we consider the entrance of the separation zone as the reference point $(X=0)$ and denote the position of the advancing meniscus with respect to this origin as $X_{\mathrm{a}}(T)$ and the position of the receding meniscus as $X_{\mathrm{r}}(T)$ (see Figure 2). We consider that the advancing meniscus reaches the origin, that is, the first capillary, at time $T=0$, such that $X_{\mathrm{a}}(0)=0$. In the following, we consider two different stages, namely, stage I in which the separator achieves stable separation and stage II for which the separator approaches critical breakthrough conditions. As shown below, the crucial difference between these two stages is that during the stage I, the advancing interface is stationary, whereas the receding interface is moving. On the other hand, during the stage II, both interfaces are moving toward the gas outlet.
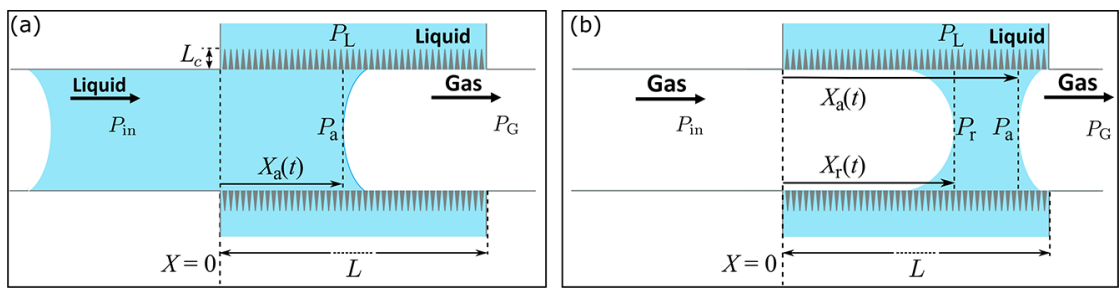

Figure 2. Schematic representation of gas-liquid separation in the microseparator. (a) A liquid slug enters the separation zone of length $L$, and we denote the position of the advancing interface with respect to the first capillary as $X_{\mathrm{a}}(t)$. The liquid flows through the capillaries of length $L_{c}$. $(\mathrm{b})$ When the receding interface enters the separation zone, its position is denoted as $X_{\mathrm{r}}(t) . P_{\mathrm{a}}$ is the liquid-side pressure at the advancing interface, and $P_{\mathrm{r}}$ is the liquid-side pressure at the receding interface. $P_{\mathrm{in}}$ is the total inlet pressure, whereas $P_{\mathrm{G}}$ and $P_{\mathrm{L}}$ are the gas outlet and liquid outlet pressures, respectively, controlled by the user. 
Stage I: Stable Separation. As the slug enters the separation zone, we denote the mass of the part of the slug in contact with the microcapillaries as $M$, which is given by

$$
M(T)=\rho A X_{\mathrm{a}}(T)
$$

where $\rho$ is the density of the liquid. This mass changes over time due to the inflow of liquid that enters the separation zone, which is given by $Q_{I} \rho$, and the outflow of liquid through the capillaries $\left(M_{\text {outflow }}\right)$, given by

$$
\frac{\mathrm{d} M_{\text {outflow }}(T)}{\mathrm{d} T}=Q_{\mathrm{c}} \rho N \frac{X_{\mathrm{a}}(T)}{L}
$$

where $Q_{c}$ is the local flow rate through each capillary, $N$ is the total number of capillaries, and $L$ is the length of the separation zone (see Figure 2). During stable separation, as not all capillaries are available for separation, $M_{\text {outflow }}$ is the flow through the total number of capillaries $(N)$ scaled by the position of the advancing meniscus in the separation zone $\left(X_{a}\right)$ with regards to the total length of the separation zone, $L$. From a mass balance of the liquid slug undergoing separation under these inflow and outflow conditions as given in eq 4, we get

$$
\frac{\mathrm{d} M(T)}{\mathrm{d} T}=Q_{\mathrm{L}} \rho-Q_{\mathrm{c}} \rho N \frac{X_{\mathrm{a}}(T)}{L}
$$

Substituting eq 3 in eq 5 and rearranging for $X_{a}$, we find

$$
\frac{\mathrm{d} X_{\mathrm{a}}}{\mathrm{d} T}=\frac{Q_{\mathrm{L}}}{A}-Q_{\mathrm{c}} \frac{N}{A L} X_{\mathrm{a}}
$$

We now estimate the local flow rate, $Q_{0}$ at each capillary by making use of a local Hagen-Poiseuille law

$$
Q_{c}=\frac{A_{c}^{2}}{\alpha \eta L_{c}} \Delta P_{c}
$$

where $\eta$ is the viscosity, $L_{\mathrm{c}}$ is the length of the capillaries, and $\alpha$ is a geometrical correction for a single capillary (refer to the works of Mortensen et al. ${ }^{25}$ or Bahrami et al. ${ }^{27}$ ). The pressure difference $\Delta P_{\mathrm{c}}$ is given by the pressure drop along each capillary: $\Delta P_{\mathrm{c}}=P_{\mathrm{a}}-P_{\mathrm{L}}$, where $P_{\mathrm{a}}$ is the pressure at the advancing interface and can be estimated as $P_{\mathrm{a}}=P_{\mathrm{G}}-P_{\mathrm{c}}$, so that

$$
\Delta P_{\mathrm{c}}=P_{\mathrm{G}}-P_{\mathrm{L}}-P_{\mathrm{c}}=\Delta P_{\mathrm{GL}}-P_{\mathrm{c}}
$$

Here, $P_{\mathrm{c}}$ is the capillary pressure of the advancing interface in the main channel, calculated from the Young-Laplace equation similar to the form shown in eq 1. $\Delta P_{\mathrm{GL}}=P_{\mathrm{G}}-$ $P_{\mathrm{L}}$ is the controlled pressure drop of the microseparator.

We introduce nondimensional variables by taking the length of the separation zone, $L$ as the length scale, $T_{0}=L / U_{0}$ as the time scale, and $P_{0}=\eta U_{0} / L_{\mathrm{c}}$ as the pressure scale, where $U_{0}=$ $Q_{G} / A$ is the typical speed given by the constant gas flow rate $Q_{G}$. With these considerations, the differential eq 6 becomes

$$
\frac{\mathrm{d} x_{\mathrm{a}}}{\mathrm{d} t}=q_{\mathrm{L}}-\beta \Delta p x_{\mathrm{a}}
$$

where we have defined $x_{\mathrm{a}}=X_{\mathrm{a}} / L$, the dimensionless pressure drop $\Delta p=\left(\Delta P_{\mathrm{GL}}-P_{\mathrm{c}}\right) / P_{0}$, the dimensionless time $t=T / T_{0}$, the dimensionless liquid flow rate $q_{\mathrm{L}}=\mathrm{Q}_{\mathrm{L}} / \mathrm{Q}_{\mathrm{G}}$, and the parameter

$$
\beta=N A_{\mathrm{c}}^{2} / \alpha A L_{\mathrm{c}}^{2}
$$

Solving eq 9 with the condition $x_{\mathrm{a}}(0)=0$, we obtain

$$
x_{\mathrm{a}}(t)=\frac{q_{\mathrm{L}}}{\beta \Delta p}\left(1-e^{-\beta \Delta p t}\right)
$$

On the other hand, the position of the receding interface, $X_{\mathrm{r}}$, can be described as $X_{\mathrm{r}}=U \cdot T-L_{0}$, based on the gas bubble moving at a constant speed, $U=Q_{T} / A$. In dimensionless units, where $x_{\mathrm{r}}=X_{\mathrm{r}} / L$, we have

$$
x_{\mathrm{r}}(t)=q_{\mathrm{T}} t-l_{0}
$$

where $l_{0}=L_{0} / L, q_{\mathrm{T}}=Q_{\mathrm{T}} / Q_{\mathrm{G}}$, and $L_{0}$ is the initial length of the liquid slugs. We note that we do not consider any slip effects due to thin liquid films on the wall. Because we are only interested in the dynamics of the liquid slug inside the separation zone, any possible effect of slip on the gas bubble velocity can be neglected as any liquid along the walls is imbibed through the capillaries. As shown below, our results indicate that this is a reasonable assumption. When the receding interface enters the separation zone, that is, $x_{\mathrm{r}}(t)=0$ in eq 12 , we get

$$
t=l_{0} / q_{\mathrm{T}}
$$

At this time $t$, the advancing interface is at location $x_{\mathrm{p}}$, obtained by substituting eq 13 in eq 11 :

$$
x_{\mathrm{p}}=\frac{q_{\mathrm{L}}}{\beta \Delta p}\left(1-e^{-\beta \Delta p l_{0} / q_{\mathrm{T}}}\right)
$$

In the stage I considered here for which separation is stable, we assume that the advancing meniscus is always pinned, that is, the advancing meniscus is stationary with $x_{\mathrm{p}}$ constant, after the receding meniscus has entered the separation zone, as reported experimentally in other studies. ${ }^{17,19}$ Note that $x_{\mathrm{p}}$ is always $<1$ and at $t=l_{0} / q_{\mathrm{T}}$, the receding meniscus enters the separation zone, that is, $x_{\mathrm{r}}\left(l_{0} / q_{\mathrm{T}}\right)=0$, and hence, the dimensionless length of the slug is at this point $l_{\mathrm{s}}\left(l_{0} / q_{\mathrm{T}}\right)=x_{\mathrm{a}}$ $-x_{\mathrm{r}}=x_{\mathrm{p}}$. Because the receding interface moves at the constant speed of $q_{\mathrm{T}} t$, the length of the slug decreases linearly as

$$
l_{\mathrm{s}}(t)=x_{\mathrm{p}}-q_{\mathrm{T}} t
$$

where we have considered that $t=0$ is the time when the receding interface enters the separation zone.

Stage II: Critical Conditions. For a given flow rate, as the pressure difference $\Delta P_{\mathrm{GL}}$ is decreased, the advancing meniscus may not reach a pinned position before the receding meniscus enters the separation zone. Under these conditions, the variation of the liquid slug length is not linear, and eq 15 needs to be modified to account for the dynamics of the advancing interface. In particular, we note that the outflow of liquid through the capillaries as in eq 4 is now given by

$$
\frac{\mathrm{d} M_{\text {outflow }}(T)}{\mathrm{d} T}=Q_{\mathrm{c}} \rho N \frac{X_{\mathrm{a}}(T)-X_{\mathrm{r}}(T)}{L}
$$

where $X_{\mathrm{r}}(T)$ is the location of the receding interface. Following the same mass balance as in eq 5 to obtain eq 9 , we now arrive at

$$
\begin{aligned}
\frac{\mathrm{d} x_{\mathrm{a}}}{\mathrm{d} t} & =q_{\mathrm{L}}-\beta \Delta p\left(x_{\mathrm{a}}-x_{\mathrm{r}}\right) \\
\frac{\mathrm{d} x_{\mathrm{r}}}{\mathrm{d} t} & =q_{\mathrm{T}}
\end{aligned}
$$

Equations 17 and 18 can be combined to get 


$$
\frac{\mathrm{d} l_{\mathrm{s}}}{\mathrm{d} t}+\beta \Delta p l_{\mathrm{s}}=-1
$$

where, $l_{\mathrm{s}}(t)=x_{\mathrm{a}}-x_{\mathrm{r}}, q_{\mathrm{L}}-q_{\mathrm{T}}=-1$, and $\Delta p=\left(\Delta P_{\mathrm{GL}}-P_{\mathrm{c}}\right) / P_{0}$, as defined above. We note that the location $x_{\mathrm{p}}$ given by eq 14 corresponds to the location of the advancing interface when the receding interface enters the separation zone. Therefore, we solve the differential eq 19 with the condition $l_{s}(0)=x_{\mathrm{p}}$ to obtain

$$
l_{\mathrm{s}}(t)=\left(x_{\mathrm{p}}+\frac{1}{\beta \Delta p}\right) e^{-\beta \Delta p t}-\frac{1}{\beta \Delta p}
$$

For a given flow rate, the liquid-to-gas breakthrough occurs when $l_{\mathrm{s}}=0$ and $x_{\mathrm{r}}=1$, namely, when the slug length is zero and at the same time, the receding meniscus is at the exit of the separation zone. Because $x_{\mathrm{r}}(t)=q_{\mathrm{T}} t$, this condition is given by

$$
\Delta p_{\mathrm{L}>\mathrm{G}}=\frac{1}{\beta} q_{\mathrm{T}} \ln \left[1+q_{\mathrm{L}}\left(1-e^{-\beta \Delta p_{\mathrm{L}>\mathrm{G}} l_{0} / q_{\mathrm{T}}}\right)\right]
$$

where we have used eq 14 . If the initial length of the slugs, $l_{0}$, is sufficiently large, we can approximate $e^{-\beta \Delta p_{\mathrm{L}>\mathrm{G}} l_{0} / q_{\mathrm{T}}} \approx 0$, and so we have

$$
\Delta p_{\mathrm{L}>\mathrm{G}} \approx \frac{1}{\beta} q_{\mathrm{T}} \ln q_{\mathrm{T}}
$$

We note that as expected, if the liquid flow rate is zero, $q_{\mathrm{L}}=$ 0 , we then have $q_{\mathrm{T}}=1$ and $\Delta p_{\mathrm{L}>\mathrm{G}}=0$. The developed model from eqs 21 and 22 captures the dynamics of a liquid slug during separation and yields a nonlinear behavior of the liquidto-gas breakthrough pressures, as opposed to a linear estimation from eq 2, which has been proposed so far in the literature. ${ }^{15,19,21,23}$ This breakthrough pressure can be dimensionalized with $P_{0}$ and can be expressed as

$$
\Delta P_{\mathrm{L}>\mathrm{G}} \approx \frac{P_{0}}{\beta} \frac{Q_{\mathrm{T}}}{Q_{G}} \ln \frac{Q_{\mathrm{T}}}{Q_{G}}+P_{\mathrm{C}}
$$

\section{RESULTS AND DISCUSSION}

Initial Observations of Stable Separation. The separation of the water-nitrogen-segmented flow was tested in the two microseparation devices, A-1 and A-2 (see Table S1 and Figure $\mathrm{S} 1$ in the Supporting Information for the design parameters), at varying liquid flow rates $\left(Q_{L}\right)$ and a constant gas flow rate $Q_{G}$ of $350 \mu \mathrm{L}_{\mathrm{n}} / \mathrm{min}$. The two devices had different capillary geometry and number of capillaries. Capillaries with a tapered geometry, as first reported by Günther et al., ${ }^{17}$ have a higher throughput in comparison with rectangular geometries. Although the tapered capillaries provide comparable $\Delta P_{\mathrm{G}>\mathrm{L}}$ values as that of rectangular capillaries, the $\Delta P_{\mathrm{L}>\mathrm{G}}$ values are lowered. For a given pressure drop across each capillary $\left(\Delta P_{c}\right), Q_{c}$ is higher in tapered capillaries due to a larger cross-sectional area $\left(A_{c}\right)$ and thus the operating zone of such microseparation devices is improved. ${ }^{19}$ The pressure difference $\left(\Delta P_{\mathrm{GL}}\right)$, which is the difference between the gas outlet pressure $\left(P_{G}\right.$ at $P_{2}$ in Figure 1$)$ and the liquid outlet pressure $\left(P_{\mathrm{L}}\right.$ at $\mathrm{P}_{3}$ in Figure 1$)$, was controlled with the help of BPRs and monitored using pressure sensors connected to LabView via a data acquisition board. The pressure drop between the separation zone and the pressure monitoring points at the outlets was considered to be negligible, as shown in the Gas-Liquid Separation Procedure section. For all experiments performed, $\Delta P_{\mathrm{GL}}$ was first set at a suitable value at which stable separation occurred using only gas flow (nitrogen) followed by the injection of water (to initiate segmented flow). The capillaries were, therefore, prewetted by the water in the slug flow to avoid the collection of the dispersed phase (nitrogen) inside the capillaries. This is because capillary prewetting, which is often overlooked, is an important factor that affects the capillary pressures and thus the operability of the device. Once the device was appropriately prewetted with water (the wetting phase), the capillaries were observed to be filled with water, and the flow through the capillaries during separation was pressure driven as described by the Hagen-Poiseuille law (eq 7). Gas-liquid separation in the A-1 device was observed using high-speed imaging as shown in Figure 3. The gas bubble approaching the

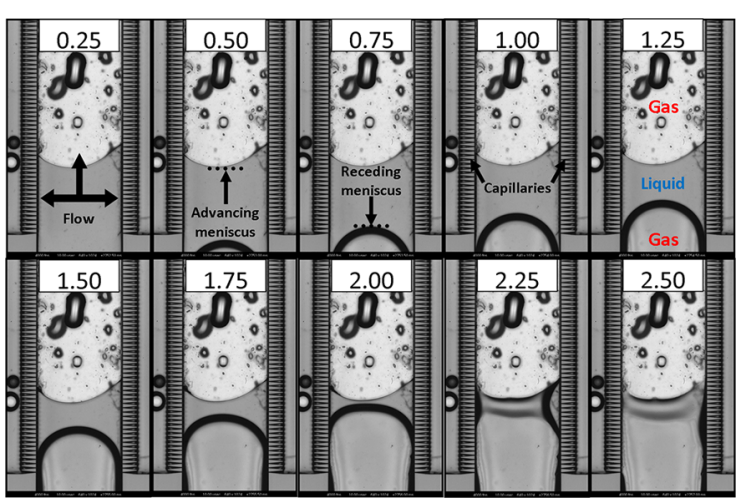

Figure 3. Sequence of high-speed images of a liquid slug in the separation zone during stable separation in the A-1 device, with gas flow rate $Q_{G}=350 \mu \mathrm{L}_{\mathrm{n}} / \mathrm{min}$ and liquid flow rate $Q_{\mathrm{L}}=90 \mu \mathrm{L} / \mathrm{min}$ at outlet pressure difference $\Delta P_{\mathrm{GL}}=7 \mathrm{kPa}$. The advancing meniscus is observed to be pinned as all the liquid exits through the capillaries. The inset labels represent the observation time in milliseconds. The flow is from the bottom to top. Images were recorded at 4000 frames/ s.

advancing meniscus was covered by a liquid film, whereas the gas phase toward the gas outlet was devoid of it (see Figures 3 and 4). This was because the trailing film of the preceding gas bubble had sufficient time to coalesce into water droplets as can be seen in the main channel (also see Supplementary Movie 2 for the entire sequence of water separating at $Q_{L}=90$ $\mu \mathrm{L} / \mathrm{min}$ and the immediate coalescence of the liquid film into water droplets in the channel). These droplets were consequently filtered out from the images so as to accurately identify only the liquid slug menisci. At stable separation conditions, the advancing meniscus was observed to be pinned inside the separation zone.

In the first instance, high-speed images were taken at the entrance of the A-1 device (upstream of the separation zone) during stable separation, and the initial length of the slugs, $L_{0}$, and number of capillaries used for separation were measured via Image J. ${ }^{34}$ It was observed that the number of capillaries that were active during separation increased with decreasing $\Delta P_{\mathrm{GL}}$ (Figure $\mathrm{S} 4 \mathrm{c}$ of the Supporting Information) because the advancing meniscus moved further inside the separation zone as $\Delta P_{\mathrm{GL}}$ approached the liquid-to-gas breakthrough pressures $\left(\Delta P_{\mathrm{L}>\mathrm{G}}\right)$. On the other hand, the number of active capillaries increased with increasing $Q_{\mathrm{L}}$ (Figure 4 and Figure S4d of the Supporting Information). 


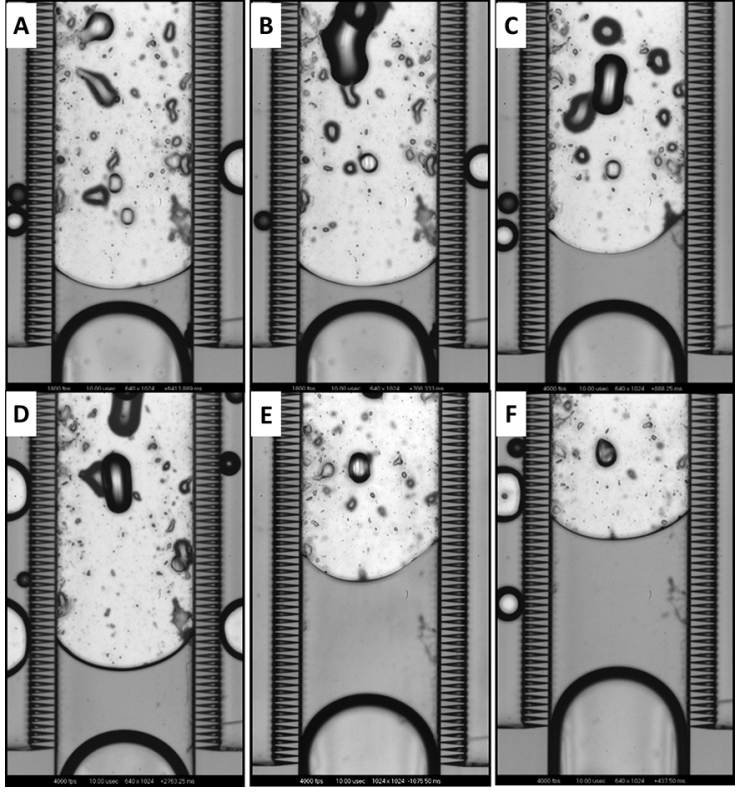

Figure 4. Snapshots of high-speed images showing the position of the advancing meniscus inside the separation zone, as a function of liquid flow rate, during stable separation in the A-1 device. Gas flow rate $Q_{G}$ $=350 \mu \mathrm{L}_{\mathrm{n}} / \mathrm{min}$ with varying liquid flow rates $\mathrm{Q}_{\mathrm{L}}=$ (A) $9 \mu \mathrm{L} / \mathrm{min},(\mathrm{B})$ $20 \mu \mathrm{L} / \mathrm{min},(\mathrm{C}) 90 \mu \mathrm{L} / \mathrm{min}$, (D) $120 \mu \mathrm{L} / \mathrm{min}$, (E) $150 \mu \mathrm{L} / \mathrm{min}$, and (F) $200 \mu \mathrm{L} / \mathrm{min}$ at outlet pressure difference $\Delta P_{\mathrm{GL}}=7 \mathrm{kPa}$. The flow is from the bottom to top. Images were recorded at 4000 frames/s.

A significant fluctuation in the pinning positions, however, was observed, especially as the gas-to-liquid and liquid-to-gas breakthrough pressures converged at high $Q_{L}$, thus reducing the operability window. Accurate control of the pressure difference, which affects the pinning position of the advancing menisci of the liquid slugs, became progressively harder even with the use of low-range, high-sensitivity BPRs. At high flow rates, where the net inflow of liquid into the separation zone was high, the pressure fluctuations were caused when the advancing meniscus instantaneously became stationary. Because of this highly dynamic nature of separation, small gas bubbles were observed to enter the liquid collection ducts through the capillaries due to local instabilities in pressure as seen on the left side of the images in Figures 3 and 4. These gas bubbles were not observed to affect the separation, and the occurrence of such events was sporadic and at random locations in the capillary array. The liquid in the liquid collection ducts was considered to have a uniform pressure drop until the outlets of the device, as it was observed to be devoid of any gas bubbles.

The initial slug lengths, $L_{0}$, which influence the liquid-to-gas breakthrough pressures, ${ }^{19,21}$ seemed fairly constant at around $70 \mathrm{~mm}$ at varying $\Delta P_{\mathrm{GL}}$, where stable separation was observed (Figure S4a of the Supporting Information). The length of slugs was measured during the process of separation with a significant pressure drop across the main channel along with the aforementioned pressure fluctuations. The formation of slug flow depends on the pressure difference between the continuous and dispersed phases, as well as on the interfacial tension, and is affected by the pressure changes at the separation zone. ${ }^{23}$ During the slug formation at the T-junction, the dispersed bubble enters the main stream and elongates. During this phase, before the bubble pinches-off from the dispersed phase inlet, the continuous phase pressure increases and pushes more fluid through the film around the dispersed bubble, whereas the dispersed phase pressure remains constant. During stable separation, the pinning of the advancing meniscus of the liquid slug in the separation zone creates an instantaneous increase in the slug flow pressure upstream. Additionally, the two-phase flow separates into two single-phase flows in the separation zone, with the continuous phase bifurcating into two liquid outlet streams, leading to a varying pressure field. Furthermore, the difference between $P_{\text {in }}$ and $P_{\mathrm{G}}$, which is directly proportional to $Q_{U}$, ranged between $3-17 \mathrm{kPa}$ (as seen in Figure S2 of the Supporting Information). At these pressure drops, the gas bubble is expected to expand gradually, and consequently, the local velocity of the liquid slug increases. This in turn leads to a decrease in the liquid slug length along the length of the main channel before reaching the capillary array. Under such conditions, for an accurate estimation of liquid slug lengths $\left(L_{0}\right)$ in systems with significant pressure drops, the readers can refer to the work reported by Molla et al. ${ }^{35}$ alongside the scaling law proposed by Garstecki et al. ${ }^{28}$
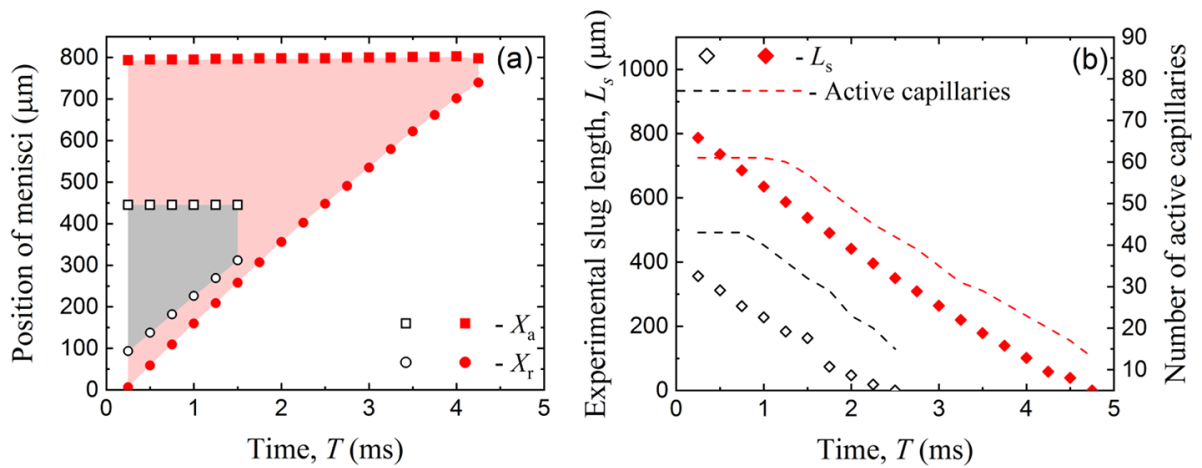

Figure 5. Tracking of liquid slugs during stable separation in the A-1 device. (a) Positions of the advancing (square markers, $X_{\mathrm{a}}$ ) and receding (circle markers, $X_{\mathrm{r}}$ ) menisci from the first capillary. The graph shows the linear motion of the receding meniscus toward the pinned advancing meniscus as liquid separates through the capillaries. Liquid flow rate $Q_{\mathrm{L}}=90 \mu \mathrm{L} / \mathrm{min}$ (black, open markers) and $200 \mu \mathrm{L} / \mathrm{min}$ (red, closed markers) at gas flow rate $Q_{\mathrm{G}}=350 \mu \mathrm{L}_{\mathrm{n}} / \mathrm{min}$ and outlet pressure difference $\Delta P_{\mathrm{GL}}=7.03 \mathrm{kPa}$. (b) The diamond markers show the length of the liquid slugs $\left(L_{\mathrm{s}}=X_{\mathrm{a}}-X_{\mathrm{r}}\right)$ within the separation zone measured between the meniscus caps. Dashed lines denote the number of active capillaries as the receding meniscus enters the separation zone. $Q_{\mathrm{L}}=90 \mu \mathrm{L} / \mathrm{min}$ (black, open markers) and $200 \mu \mathrm{L} / \mathrm{min}$ (red, closed markers) at $Q_{\mathrm{G}}=350 \mu \mathrm{L}_{\mathrm{n}} / \mathrm{min}$ and $\Delta P_{\mathrm{GL}}=7.03 \mathrm{kPa}$. 

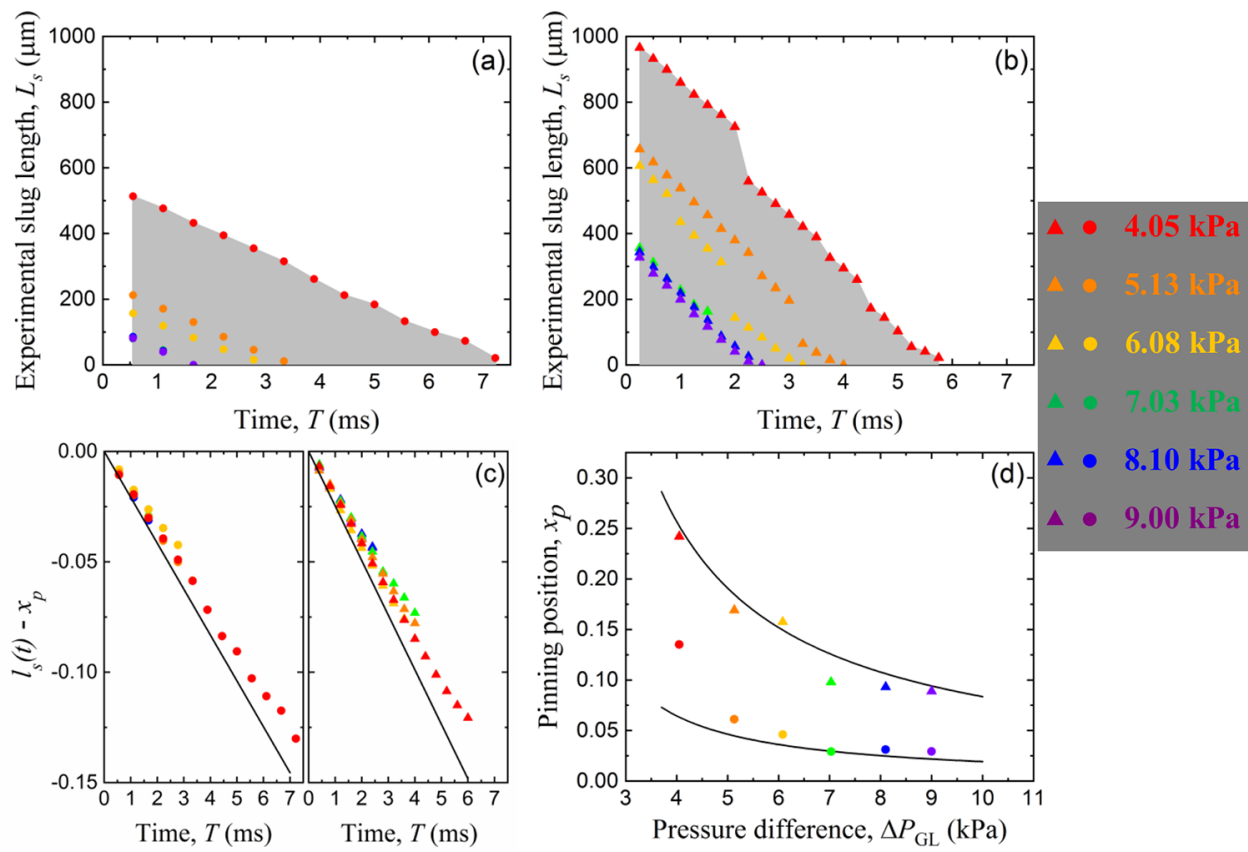

Figure 6. (a, b) Liquid slug lengths $\left(L_{\mathrm{s}}=X_{\mathrm{a}}-X_{\mathrm{r}}\right)$ during stable separation in the A-1 device at a liquid flow rate $Q_{\mathrm{L}}=20 \mu \mathrm{L} / \mathrm{min}$ (circle markers) and $90 \mu \mathrm{L} / \mathrm{min}$ (triangle markers) with a gas flow rate $Q_{\mathrm{G}}=350 \mu \mathrm{L}_{\mathrm{n}} / \mathrm{min}$. The outlet pressure difference $\Delta P_{\mathrm{GL}}$ was varied as follows: $4.05 \mathrm{kPa}$ (red), $5.13 \mathrm{kPa}$ (orange), $6.08 \mathrm{kPa}$ (yellow), $7.03 \mathrm{kPa}$ (green), $8.1 \mathrm{kPa}$ (blue), and $9.0 \mathrm{kPa}$ (violet). Although the rate of decrease of slug lengths remained constant, the pinning distance of the advancing meniscus decreased with increasing $\Delta P_{\mathrm{GL}}$. (c) Subtracting the experimentally measured slug lengths from the pinning position (markers) for $Q_{\mathrm{L}}=20 \mu \mathrm{L} / \mathrm{min}$ (left) and $90 \mu \mathrm{L} / \mathrm{min}$ (right) yields a linear behavior (solid lines), where $l_{\mathrm{s}}(t)$ is the dimensionless length of the liquid slugs. (d) Pinning positions of the advancing meniscus (lines) compared with that of the experiments (markers) for two flow rates, $Q_{\mathrm{L}}=20 \mu \mathrm{L} / \mathrm{min}$ (circle markers) and $90 \mu \mathrm{L} / \mathrm{min}$ (triangle markers) at $Q_{\mathrm{G}}=350 \mu \mathrm{L}_{\mathrm{n}} / \mathrm{min}$. The lines were obtained by fitting eq 14 to the experimental data, where $\beta$ was used as the fitting parameter. For this device, $\beta=2.5 \times 10^{-4}$ was obtained from the pinning position $\left(x_{\mathrm{p}}\right)$ vs $\Delta P_{\mathrm{GL}}$ plots.

Slug Flow Characteristics: Stable Separation. Highspeed imaging was performed to investigate gas-liquid separation in the A-1 device, as described earlier. At stable separation pressures (stage I), the front end of the liquid slug (advancing meniscus) was observed to be pinned inside the capillary zone $\left(X_{\mathrm{a}}\right.$ is constant in Figure 5), where all the capillaries downstream were inactive for liquid separation. Such pinning behavior has been observed previously. ${ }^{17-19}$

The image analysis algorithm was used to track the positions of the menisci from the point of entry of the receding menisci (i.e., from the third frame in Figure 3), and the liquid slug lengths and number of active capillaries were calculated (Figure 5 and Supplementary Movie 1). We observed that in the separation zone, the advancing meniscus is pinned, whereas the receding meniscus approached it linearly, as suggested by eq 15. It is also worth noting that, because of the curvature of the menisci, the number of active capillaries initially remained constant after the cap of the receding meniscus entered the separation zone (see dashed lines in Figure 5b). Similarly, when the two meniscus caps touched each other (hence, achieving complete separation, i.e., the eighth frame of Figure 3 ), both the distance between the two menisci at the edges of the capillaries and the number of active capillaries remained larger than zero due to the curvature of the menisci.

Varying the pressure difference $\Delta P_{\mathrm{GL}}$ during separation showed that the rate of decrease in the lengths of the liquid slugs $\left(L_{\mathrm{s}}=X_{\mathrm{a}}-X_{\mathrm{r}}\right)$ remained constant (slopes of the datasets in Figures $6 \mathrm{a}, \mathrm{b}$ ), while only their position inside the separation zone varied, that is, the pinning positions ( $y$ intercepts in Figure $6 \mathrm{a}, \mathrm{b})$. Figure $6 \mathrm{c}$ depicts experimental data of the slug length normalized with the separation length $(L)$ for different values of $\Delta P_{\mathrm{GL}}$. It was observed that for a given flow rate, all data collapse into the same linear behavior as predicted by eq 15. It is worth noting that such linear behavior is independent of variation in $\Delta P_{\mathrm{GL}}$ and only depends on the flow rate. Also, we note that the good agreement observed between the experiments and the theoretical behavior given by eq 15 indicates that the assumption made in the model, namely, the negligible slip velocity of the gas bubble inside the separation zone, is justified. The experiments in Figure $6 \mathrm{~d}$ indicated that the slug became pinned further inside the capillary zone with decreasing $\Delta P_{\mathrm{GL}}$. For estimating the pressure drop along each capillary, $\Delta P_{\mathrm{c}}$ in eq 8 , which affects the pinning position $\left(x_{\mathrm{p}}\right)$, the capillary pressure of the advancing interface in the main channel $\left(P_{\mathrm{c}}\right)$ was required. $P_{\mathrm{c}}$ was estimated from the YoungLaplace equation of the form as in eq 1 and required the contact angle of the advancing meniscus and the surface tension of the liquid. Quantification of the apparent contact angle of the advancing menisci was a challenge due to the presence of droplet coalescence of the liquid slug with the droplets accumulated on the channel surfaces (due to their hydrophilicity) that led to changes in the curvature of the menisci. Various estimations exist in the literature obtained by either measuring the static contact angle in a pore ${ }^{36}$ or considering the dependence of dynamic contact angles on the fluid velocity. ${ }^{37-39}$ Here, we took an equilibrium contact angle of $20^{\circ}$ (air-water-glass combination ${ }^{36}$ ) for the advancing meniscus to calculate $P_{\mathrm{c}}$.

Equation 14 was fitted to the experimentally measured pinning positions of the advancing meniscus as shown in Figure 6d. For the data fit, $\beta$, which depends on the capillary geometry, was used as the fitting parameter. The value was 

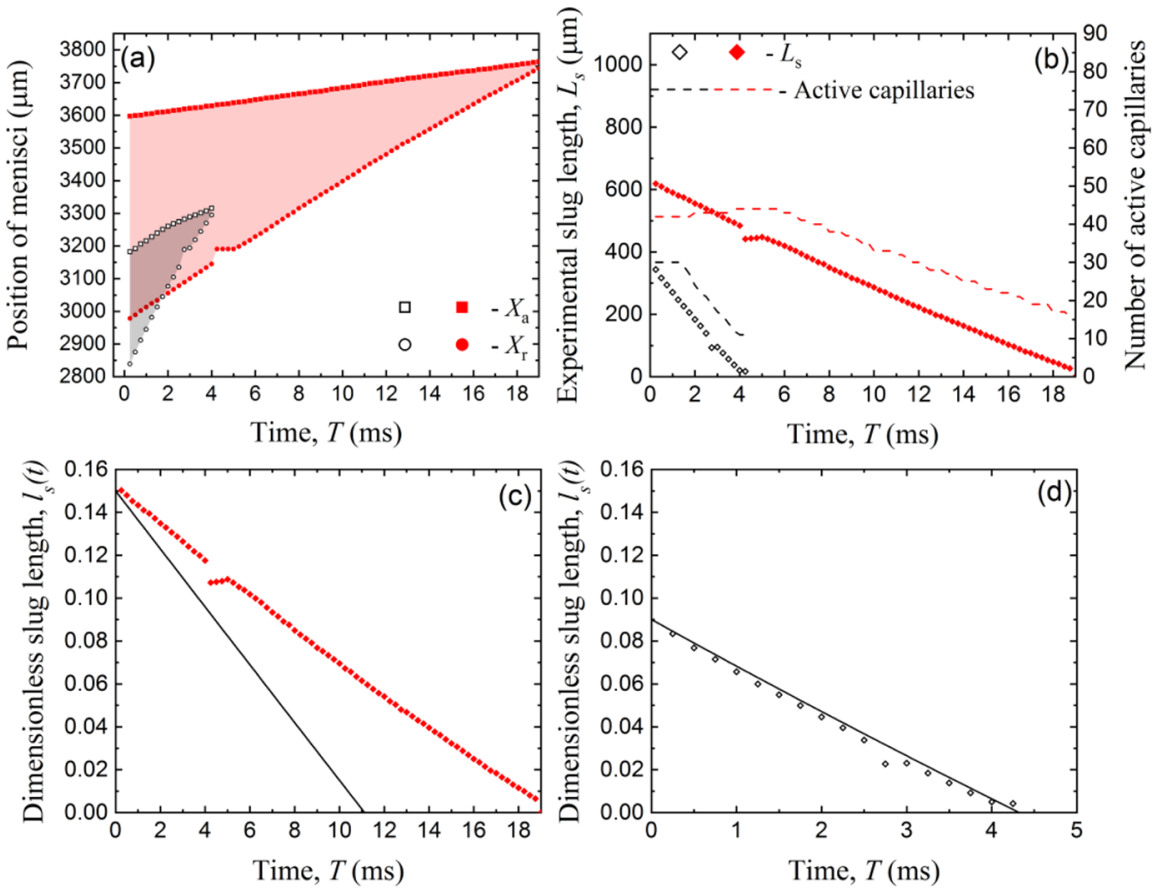

Figure 7. Tracking of liquid slugs at critical conditions in the A-1 device (i.e., last slug to completely separate before liquid breakthrough). (a) Positions of the advancing (square markers, $X_{\mathrm{a}}$ ) and receding (circle markers, $X_{\mathrm{r}}$ ) menisci from the first capillary. The graph shows the motion of the receding meniscus toward the nonstatic advancing meniscus as liquid separates through the capillaries. (b) The diamond markers show the length of the liquid slugs $\left(L_{\mathrm{s}}=X_{\mathrm{a}}-X_{\mathrm{r}}\right)$ within the separation zone measured between the meniscus caps. Dashed lines denote the number of active capillaries as the receding meniscus approaches the advancing meniscus. The liquid flow rate $Q_{\mathrm{L}}=20 \mu \mathrm{L} / \mathrm{min}$ (red, closed markers) at an outlet pressure difference $\Delta P_{\mathrm{GL}, \text { critical }}=0.78 \mathrm{kPa}$ and $90 \mu \mathrm{L} / \mathrm{min}$ (black, open markers) at $\Delta P_{\mathrm{GL}, \text { critical }}=2.62 \mathrm{kPa}$; both with a constant gas flow rate $Q_{\mathrm{G}}=$ $350 \mu \mathrm{L}_{\mathrm{n}} / \mathrm{min}$. (c, d) Comparison of the dimensionless slug length, $l_{\mathrm{s}}(t)$, experimentally measured (markers) with eq 20 (solid lines) at (c) $Q_{\mathrm{L}}=20$ $\mu \mathrm{L} / \mathrm{min}$ and $(\mathrm{d}) Q_{\mathrm{L}}=90 \mu \mathrm{L} / \mathrm{min}$.

obtained by minimizing the error in the least-squares fit, considering both the data sets in Figure $6 \mathrm{~d}$ simultaneously. For this particular A-1 device, we obtained $\beta=2.5 \times 10^{-4}$. The behavior of the advancing meniscus before getting pinned is shown in Figure S6 of the Supporting Information. The advancing meniscus, $x_{\mathrm{a}}(t)$, entered the separation zone and gradually reached $x_{\mathrm{p}}$ through an exponential behavior as described by eq 11 . However, coalescence of water droplets in the main channel (formed due to the hydrophilic nature of the channel surfaces) with the advancing meniscus not only affected its curvature but also led to a variability in the pinning positions. This further exemplifies the difficulty in fully characterizing the liquid slug in the separation zone. The entire timescale of the separation process is shown in Figure S7 of the Supporting Information, highlighting the fluctuations in the positions of the advancing meniscus at high liquid flow rates through the sudden movement of the meniscus just before the receding meniscus approached it.

Once $\beta$ was determined based on the capillary geometry, eqs 20 and 21 could be used to directly estimate the dynamics of the menisci of the slugs and the liquid-to-gas breakthrough pressures, as discussed below.

Slug Flow Characteristics: Critical Conditions. As the pressure difference $\Delta P_{\mathrm{GL}}$ approached the liquid-to-gas breakthrough point, the pinning effect of the advancing meniscus was no longer observed, and the liquid slug moved further into the separation zone closer to the gas outlet. We define this as the critical point just before liquid-to-gas breakthrough, that is, when a liquid slug gets completely separated just before reaching the end of the separation zone. Owing to the sensitivity of the system, the slugs following the one at the critical point were more likely to breakthrough into the gas outlet, and the system could not be maintained at the critical $\Delta P_{\mathrm{GL}}$. The flow of liquid through the capillaries took place also at the liquid-to-gas breakthrough pressure. Figure $7 \mathrm{a}, \mathrm{b}$ shows the movement of the menisci, as the advancing meniscus approaches the gas outlet ( $L=4115 \mu \mathrm{m}$ for the A-1 device) and the (decreasing) lengths of the slugs at the critical condition. At this state, both menisci were moving at different speeds, leading to a nonlinear decrease in the liquid slug length. The liquid slug lengths were normalized with the separation length $(L)$ and compared with the theoretical values given by eq 20 as shown in Figure $7 \mathrm{c}$,d using the parameter $\beta$ obtained from the previous section. We note that the observed discrepancy in Figure $7 \mathrm{c}$ could be a consequence of the aforementioned pressure sensitivity of the system.

During the liquid-to-gas breakthrough, the receding meniscus also reaches the gas outlet, and eq 21 applies. Figure 8 shows the experimental liquid-to-gas breakthrough pressures for different flow rates compared to the theoretical estimation given by eq 21 . Castell et al. ${ }^{23}$ hypothesized that a decrease in the advancing meniscus contact angle of the liquid slug with increasing flow rates and also when the meniscus entered the capillary zone was the potential reason for an increase in the breakthrough pressures with increasing flow rates. Similar behavior was also visually observed from the images of liquid slugs in the A-1 device.

Figure 8 also shows the experimental gas-to-liquid breakthrough compared to the Young-Laplace prediction, eq 1, hence providing the full operating zone of the separator. Experimental results of gas breakthrough show strong deviations from the Young-Laplace equation particularly at 


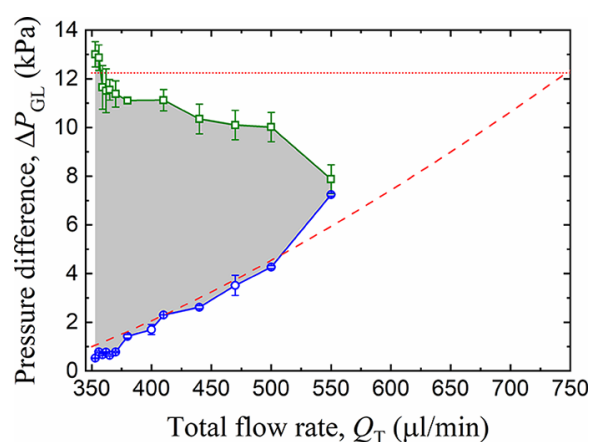

Figure 8. Operating zone of the gas-liquid separation device, A-1. Green square markers: points of gas-to-liquid breakthrough $\left(\Delta P_{\mathrm{G}>\mathrm{L}}\right)$; blue circle markers: liquid-to-gas breakthrough $\left(\Delta P_{\mathrm{L}>\mathrm{G}}\right)$. Dotted line: theoretical Young-Laplace breakthrough pressure through the capillaries; dashed line: liquid-to-gas breakthrough pressure given by eq21. $\Delta P_{\mathrm{L}>\mathrm{G}}$ from the model was obtained from the dimensionalization of $\Delta p_{\mathrm{L}>\mathrm{G}}$ in the following form: $\Delta P_{\mathrm{L}>\mathrm{G}}=\left(P_{0} \times \Delta p_{\mathrm{L}>\mathrm{G}}\right)+P_{\mathrm{c}}$. The gas flow rate $\left(Q_{\mathrm{G}}\right)$ was $350 \mu \mathrm{L}_{\mathrm{n}} / \mathrm{min}$.

high flow rates, indicating that such theoretical approach may no longer be valid, thus necessitating a detailed investigation of the apparent contact angles of the menisci inside the capillaries.

Phase Separation in Separator A-2. To further investigate the ability of the model given by eq 21 to predict liquid-to-gas breakthrough, we performed additional gasliquid separation studies in a different microseparator device, which we denote as A-2 (see Table S1 of the Supporting Information). The water-nitrogen-segmented flow was separated using this device via the same procedure adopted before. Characteristics of the slug flow in the separation zone were analyzed at two different flow rates and varying $\Delta P_{\mathrm{GL}}$ (see Figure $S 8$ of the Supporting Information). The events occurring during separation were found in general agreement with the model, namely, the linearity in the decrease of slug length and variation in the position of pinning of the advancing meniscus. The model estimated the pinning positions in the A2 device for both the flow rates as shown in Figure 9a from eq 14 by fitting the parameter $\beta$, as described before, to a value of $2.1 \times 10^{-4}$. This value was then used to calculate the liquid-togas breakthrough pressures in the A-2 device as shown in
Figure $9 \mathrm{~b}$, which was compared with experimentally measured breakthrough values. The fitted $\beta$ values were observed to be similar for the A-1 and A-2 devices, as the cross-sectional geometry of both the capillary designs was similar but with different number of capillaries and channel depths. In the A-2 device, the capillaries were farther apart $(R=45 \mu \mathrm{m}$, see Table $S 1$ in the Supporting Information) than that of the A-1 device $(R=25 \mu \mathrm{m})$. Although the pressure drop across a single capillary is expected to be similar between the two devices, the fewer number of capillaries in the A-2 device $(N=160)$ resulted in a lower $\beta$ value, thus leading to a lower outflow of liquid through the capillary array in comparison with that of the A-1 device with $N=276$. For capillaries with nonparallel geometry, no empirical equations currently exist, and because of the tapered geometry, a larger flow rate for a given pressure drop is anticipated in comparison with a capillary with a parallel geometry of the same length and a width equal to the capillary width facing the main channel of the tapered geometry $\left(D_{\mathrm{i}}\right)$. This property makes $\beta$ to be all the more sensitive.

We note that there is a good agreement up to values of $Q_{T}=$ $550 \mu \mathrm{L} / \mathrm{min}$ (Figure 9b) above which the theoretical estimations deviate from the experimental results. The deviations occur for $Q_{J} / Q_{G}>0.5$ in the A-2 device, which has deeper channels. This led to shorter slug lengths, and as the liquid flow rate increased, the gas bubble lengths decreased. Under these conditions, a second liquid slug can enter the separation zone before the leading liquid slug has been fully separated through the capillaries. Because of this, the overall speed of the leading slug decreases hence giving rise to a lower liquid-to-gas breakthrough pressure differences. This effect is not captured by eq 21 and explains the deviation between theory and experimental results of Figure $9 \mathrm{~b}$ for $Q_{T}>550 \mu \mathrm{L} /$ min. Additionally, the deviations may also be attributed to the errors in the manual observations of the breakthrough pressures at such high flow rates along with the variations in the etch depths in the device resulting from the DRIE process.

\section{CONCLUSIONS}

We have presented a detailed experimental study on the separation process of a gas-liquid segmented flow in capillary microseparators that have an array of capillaries on both sides
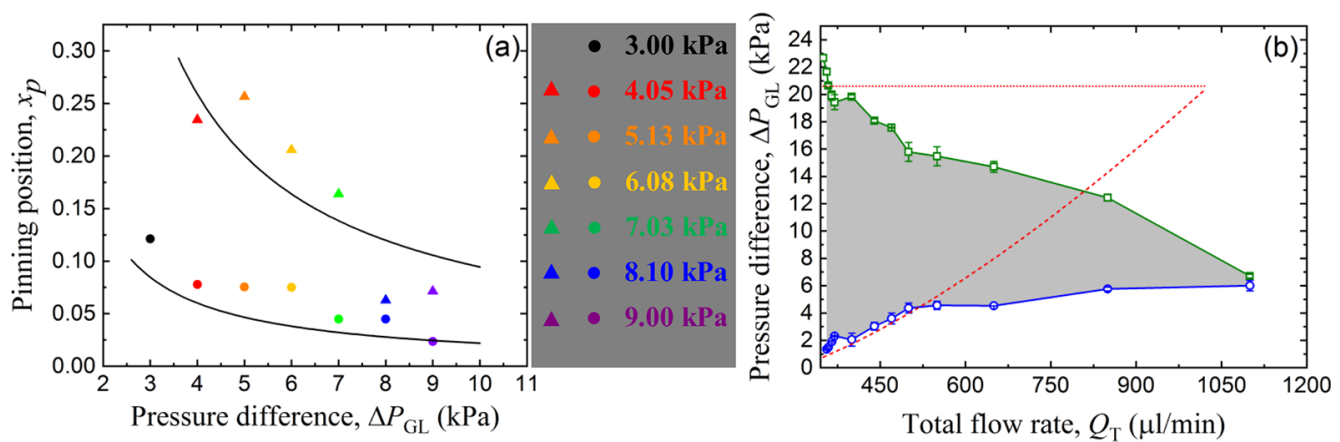

Figure 9. (a) Pinning positions of the advancing meniscus (lines obtained by fitting eq 14 with $\beta=2.1 \times 10^{-4}$ ) compared with that of the experiments (markers) for two liquid flow rates, $Q_{\mathrm{L}}=20 \mu \mathrm{L} / \mathrm{min}$ (circle markers) and $90 \mu \mathrm{L} / \mathrm{min}$ (triangle markers), at a gas flow rate $Q_{\mathrm{G}}=350$ $\mu \mathrm{L}_{\mathrm{n}} / \mathrm{min}$. The outlet pressure difference $\Delta P_{\mathrm{GL}}$ was varied as follows: $3 \mathrm{kPa}$ (black), $4.05 \mathrm{kPa}$ (red), $5.13 \mathrm{kPa}$ (orange), $6.08 \mathrm{kPa}$ (yellow), $7.03 \mathrm{kPa}$ (green), $8.1 \mathrm{kPa}$ (blue), and $9.0 \mathrm{kPa}$ (violet). (b) Liquid-to-gas breakthrough pressures $\left(\Delta P_{\mathrm{L}>\mathrm{G}}\right)$ obtained from eq 21 (dashed line) and experimentally measured values (blue circle markers) for the A-2 device. Green square markers: experimental gas-to-liquid breakthrough pressures $\left(\Delta P_{\mathrm{G}>\mathrm{L}}\right)$; horizontal dotted line: theoretical gas-to-liquid breakthrough pressures estimated from the Young-Laplace equation. $\Delta P_{\mathrm{L}>\mathrm{G}}$ from the model was obtained from the dimensionalization of $\Delta p_{\mathrm{L}>\mathrm{G}}$ in the following form: $\Delta P_{\mathrm{L}>\mathrm{G}}=\left(P_{0} \times \Delta p_{\mathrm{L}>\mathrm{G}}\right)+P_{c}$. 
of a channel. By making use of in situ optical high-speed imaging, we have been able to quantify the dynamics of the gas-liquid flow inside the separation zone. We observed that at stable separation conditions, the advancing meniscus became pinned in the separation zone, whereas the receding meniscus approached it at a constant speed, giving rise to a linear decrease of the liquid slug length. On the other hand, when the system approached critical conditions, both menisci were moving at different speeds, leading to an exponential decrease in the liquid slug length.

A hydrodynamic model based on mass conservation was developed, which estimated a linear decrease of the slug length under stable separation and an exponential decrease under critical conditions (just before liquid-to-gas breakthrough) in agreement with experiments. The model had only one fitting parameter, the geometric factor $\beta$, which was obtained from the location of the pinned position of the advancing meniscus as a function of the pressure difference between the gas outlet and the liquid outlet. Once this parameter was determined, the model predicted well the liquid-to-gas breakthrough pressures. The model was further tested against the performance of another microseparation device with different geometrical design of the capillaries and with different etch depth. The model estimated the liquid-to-gas breakthrough pressures with a good agreement up to $Q_{T}=550 \mu \mathrm{L} / \mathrm{min}$, above which more than one slug was encountered in the separation zone, which was not captured in our model.

\section{ASSOCIATED CONTENT}

\section{(5) Supporting Information}

The Supporting Information is available free of charge on the ACS Publications website at DOI: 10.1021/acs.langmuir.8b04202.

Design and operation of the microfabricated gas-liquid separation devices; image preprocessing via morphological reconstruction; measurement of the initial liquid slug length, number of active capillaries, and bubble frequency during separation; tracking the entry of the advancing meniscus in the separation zone at stable separation conditions; quantification of slug lengths in the A-2 device at varying pressure differences (PDF)

A movie of the image analysis algorithm tracking the gas-liquid menisci, recorded at $4000 \mathrm{fps}$ and played back at $3 \mathrm{fps}$ (AVI)

A video of gas-liquid separation occurring at $Q_{L}=90$ $\mu \mathrm{L} / \mathrm{min}$, recorded at $4000 \mathrm{fps}$ and every 50th frame played back at $10 \mathrm{fps}$ (AVI)

\section{AUTHOR INFORMATION}

\section{Corresponding Author}

*E-mail: a.gavriilidis@ucl.ac.uk.

\section{ORCID}

Anand N. P. Radhakrishnan: 0000-0002-9763-8830

Asterios Gavriilidis: 0000-0003-3508-5043

\section{Author Contributions}

The manuscript was written through contributions from all authors. All authors have given approval to the final version of the manuscript and declare no conflicting interests.

Notes

The authors declare no competing financial interest.

\section{ACKNOWLEDGMENTS}

We are grateful to the anonymous reviewer for valuable comments and suggestions and to Dr. Benjamin Aymard and Mr. Urbain Vaes, Imperial College London, for valuable inputs and stimulating discussion. We acknowledge financial support from the Engineering and Physical Sciences Research Council of the U.K. through grant nos. EP/L027232 and EP/L027186.

\section{NOTATION}

$\Delta p \quad$ dimensionless pressure drop, $\left(\Delta P_{\mathrm{GL}}-\Delta P_{\mathrm{c}}\right) / P_{0}$

$\Delta P_{\mathrm{G}>\mathrm{L}} \quad \Delta P_{\mathrm{GL}}$ at which gas-to-liquid breakthrough occurs $(\mathrm{kPa})$

$\Delta p_{\mathrm{L}>\mathrm{G}}$ dimensionless liquid-to-gas breakthrough pressure obtained from eq 21

$\Delta P_{\mathrm{L}>\mathrm{G}} \quad \Delta P_{\mathrm{GL}}$ at which liquid-to-gas breakthrough occurs $(\mathrm{kPa})$

$\Delta P_{\mathrm{c}} \quad$ pressure drop across a capillary $(\mathrm{kPa})$

$\Delta P_{\mathrm{GL}} \quad$ gas-liquid outlet pressure difference, $P_{\mathrm{G}}-P_{\mathrm{L}}(\mathrm{kPa})$

$A \quad$ cross-sectional area of the channel $\left(\mu \mathrm{m}^{2}\right)$

$A_{\mathrm{c}} \quad$ cross-sectional area of a capillary $\left(\mu \mathrm{m}^{2}\right)$

$D \quad$ capillary width $(\mu \mathrm{m})$

$H \quad$ channel/capillary height $(\mu \mathrm{m})$

$L \quad$ length of the separation zone ( $\mathrm{mm}$ )

$l_{0} \quad$ dimensionless initial length of the liquid slug, $L_{0} / L$

$L_{0} \quad$ initial length of the liquid slug $(\mathrm{mm})$

$L_{\mathrm{c}} \quad$ length of capillaries $(\mu \mathrm{m})$

$l_{\mathrm{s}} \quad$ dimensionless length of the liquid slug, $x_{\mathrm{a}}-x_{\mathrm{r}}$

$L_{\mathrm{s}} \quad$ length of the liquid slug in the separation zone, $X_{\mathrm{a}}-$ $X_{\mathrm{r}}(\mu \mathrm{m})$

$M \quad$ mass of the part of the slug in contact with the microcapillaries $(\mathrm{kg})$

$M_{\text {outflow }}$ mass outflow of liquid through the capillaries $(\mathrm{kg})$

$N \quad$ total number of capillaries

$P_{0} \quad$ pressure scale for nondimensionalization, $\eta U_{0} / L_{\mathrm{c}}$

$P_{\mathrm{a}} \quad$ liquid-side pressure at the advancing interface $(\mathrm{kPa})$

$P_{c} \quad$ capillary pressure of the advancing interface $(\mathrm{kPa})$

$P_{\mathrm{G}} \quad$ gas outlet pressure $(\mathrm{kPa})$

$P_{\text {in }} \quad$ total inlet pressure $(\mathrm{kPa})$

$P_{\mathrm{L}} \quad$ liquid outlet pressure $(\mathrm{kPa})$

$P_{\mathrm{r}} \quad$ liquid-side pressure at the receding interface $(\mathrm{kPa})$

$Q_{c} \quad$ local flow rate through each capillary $(\mu \mathrm{L} / \mathrm{min})$

$Q_{\mathrm{G}} \quad$ gas flow rate $\left(\mu \mathrm{L}_{\mathrm{n}} / \mathrm{min}\right)$

$q_{\mathrm{L}} \quad$ dimensionless liquid flow rate, $Q_{\mathrm{L}} / \mathrm{Q}_{\mathrm{G}}$

$Q_{\mathrm{L}} \quad$ liquid flow rate $(\mu \mathrm{L} / \mathrm{min})$

$q_{\mathrm{T}} \quad$ dimensionless total flow rate, $Q_{\mathrm{T}} / \mathrm{Q}_{\mathrm{G}}$

$Q_{\mathrm{T}} \quad$ total flow rate $(\mu \mathrm{L} / \mathrm{min})$

$t$ dimensionless time scale, $T / T_{0}$

$T \quad$ time (ms)

$T_{0} \quad$ time scale for non-dimensionalization, $L / U_{0}$

$U$ superficial average velocity of the two-phase flow $(\mathrm{mm} / \mathrm{s})$

$U_{0} \quad$ velocity term for non-dimensionalization, $Q_{G} / A$

$W \quad$ width of main channel $(\mu \mathrm{m})$

$x_{\mathrm{a}}$ dimensionless advancing meniscus position, $X_{\mathrm{a}} / L$

$X_{\mathrm{a}} \quad$ position of the advancing meniscus $(\mu \mathrm{m})$

$x_{\mathrm{p}} \quad$ pinning position of the advancing meniscus

$x_{\mathrm{r}} \quad$ dimensionless receding meniscus position, $X_{\mathrm{r}} / L$

$X_{\mathrm{r}} \quad$ position of the receding meniscus $(\mu \mathrm{m})$

\section{GREEK LETTERS}

$\alpha$ geometrical correction factor in the Hagen-Poiseuille equation 
$\beta$ modified geometrical factor presented in this work $=\mathrm{N} A_{c}^{2} /$ $\alpha A L_{\mathrm{c}}^{2}$

$\gamma$ surface tension of the liquid $(\mathrm{N} / \mathrm{m})$

$\eta$ viscosity of the liquid $(\mathrm{Pa} \cdot \mathrm{s})$

$\theta_{\mathrm{e}}$ equilibrium contact angle $\left(^{\circ}\right)$

$\rho$ density of the liquid $\left(\mathrm{kg} / \mathrm{m}^{3}\right)$

\section{REFERENCES}

(1) Lam, K. F.; Sorensen, E.; Gavriilidis, A. Review on Gas-liquid Separations in Microchannel Devices. Chem. Eng. Res. Des. 2013, 91, 1941-1953.

(2) Kenig, E. Y.; Su, Y.; Lautenschleger, A.; Chasanis, P.; Grünewald, M. Micro-Separation of Fluid Systems: A State-of-the-Art Review. Sep. Purif. Technol. 2013, 120, 245-264.

(3) Hartman, R. L.; Jensen, K. F. Microchemical Systems for Continuous-Flow Synthesis. Lab Chip 2009, 9, 2495-2507.

(4) Wellsandt, T.; Stanisch, B.; Strube, J. Development of Micro Separation Technology Modules. Part 1: Liquid-Liquid Extraction. Chemie Ing. Tech. 2015, 87, 1198-1206.

(5) Assmann, N.; Werhan, H.; Ładosz, A.; Rudolf von Rohr, P. Supercritical Extraction of Lignin Oxidation Products in a Microfluidic Device. Chem. Eng. Sci. 2013, 99, 177-183.

(6) Assmann, N.; Ładosz, A.; Rudolf von Rohr, P. Continuous Micro Liquid-Liquid Extraction. Chem. Eng. Technol. 2013, 36, 921-936.

(7) Angelescu, D. E.; Mercier, B.; Siess, D.; Schroeder, R. Microfluidic Capillary Separation and Real-Time Spectroscopic Analysis of Specific Components from Multiphase Mixtures. Anal. Chem. 2010, 82, 2412-2420.

(8) Vural Gürsel, I.; Kockmann, N.; Hessel, V. Fluidic Separation in Microstructured Devices - Concepts and their Integration into Process Flow Networks. Chem. Eng. Sci. 2017, 169, 3-17.

(9) Jaritsch, D.; Holbach, A.; Kockmann, N. Counter-Current Extraction in Microchannel Flow: Current Status and Perspectives. J. Fluids Eng. 2014, 136, 091211-091218.

(10) Li, S.; Jing, S.; Luo, Q.; Chen, J.; Luo, G. Bionic System for Countercurrent Multi-Stage Micro-Extraction. RSC Adv. 2012, 2, 10817-10820.

(11) Kraus, M.; Krewer, U. Experimental Analysis of the Separation Efficiency of an Orientation Independent Gas/Liquid Membrane Separator. Sep. Purif. Technol. 2011, 81, 347-356.

(12) Singh, A. K.; Ko, D.-H.; Vishwakarma, N. K.; Jang, S.; Min, K.I.; Kim, D.-P. Micro-Total Envelope System with Silicon Nanowire Separator for Safe Carcinogenic Chemistry. Nat. Commun. 2016, 7, 10741.

(13) TeGrotenhuis, W. E.; Stenkamp, S. V. Normal Gravity Testing of a Microchannel Phase Separator for Insitu Resource Utilization; NASA/CR-2001-210955; Washington, 2001.

(14) TeGrotenhuis, W. E.; Wegeng, R. S.; Whyatt, G. A.; Stenkamp, V. S.; Gauglitz, P. A. Microsystem Capillary Separations. US Patent US 6,666,909 B1, 2003.

(15) Kralj, J. G.; Sahoo, H. R.; Jensen, K. F. Integrated Continuous Microfluidic Liquid-Liquid Extraction. Lab Chip 2007, 7, 256-263.

(16) Adamo, A.; Heider, P. L.; Weeranoppanant, N.; Jensen, K. F. Membrane-Based, Liquid-Liquid Separator with Integrated Pressure Control. Ind. Eng. Chem. Res. 2013, 52, 10802-10808.

(17) Günther, A.; Khan, S. A.; Thalmann, M.; Trachsel, F.; Jensen, K. F. Transport and Reaction in Microscale Segmented Gas-liquid Flow. Lab Chip 2004, 4, 278-286.

(18) Günther, A.; Jhunjhunwala, M.; Thalmann, M.; Schmidt, M. A.; Jensen, K. F. Micromixing of Miscible Liquids in Segmented GasLiquid Flow. Langmuir 2005, 21, 1547-1555.

(19) Roydhouse, M. D.; Pradas, M.; Al-Rifai, N.; Azizi, B.; Cao, E.; Kalliadasis, S.; Gavriilidis, A. Operating Ranges of Gas-liquid Capillary Microseparators: Experiments and Theory. Chem. Eng. Sci. 2014, 114, 30-39.

(20) Tsai, J.-H.; Lin, L. Active Microfluidic Mixer and Gas Bubble Filter Driven by Thermal Bubble Micropump. Sensors Actuators, A 2002, 97-98, 665-671.
(21) Ładosz, A.; Rudolf von Rohr, P. Design Rules for Microscale Capillary Phase Separators. Microfluid. Nanofluid. 2017, 21, 153.

(22) Bruus, H. Theoretical Microfluidics; Oxford University Press Inc.: New York, 2008

(23) Castell, O. K.; Allender, C. J.; Barrow, D. A. Liquid-Liquid Phase Separation: Characterisation of a Novel Device Capable of Separating Particle Carrying Multiphase Flows. Lab Chip 2009, 9, 388-396.

(24) Yang, L.; Weeranoppanant, N.; Jensen, K. F. Characterization and Modeling of the Operating Curves of Membrane Microseparators. Ind. Eng. Chem. Res. 2017, 56, 12184-12191.

(25) Mortensen, N. A.; Okkels, F.; Bruus, H. Reexamination of Hagen-Poiseuille Flow: Shape Dependence of the Hydraulic Resistance in Microchannels. Phys. Rev. E 2005, 71, 057301.

(26) Günther, A.; Jensen, K. F. Multiphase Microfluidics: From Flow Characteristics to Chemical and Materials Synthesis. Lab Chip 2006, 6, 1487-1503.

(27) Bahrami, M.; Michael Yovanovich, M.; Richard Culham, J. A Novel Solution for Pressure Drop in Singly Connected Microchannels of Arbitrary Cross-Section. Int. J. Heat Mass Transfer 2007, 50, $2492-$ 2502.

(28) Garstecki, P.; Fuerstman, M. J.; Stone, H. A.; Whitesides, G. M. Formation of Droplets and Bubbles in a Microfluidic T-JunctionScaling and Mechanism of Break-Up. Lab Chip 2006, 6, 437-446.

(29) van Rossum, G. Python Tutorial, Technical Report CS-R9526; Amsterdam, 1995.

(30) van Der Walt, S.; Colbert, S. C.; Varoquaux, G. The NumPy Array: A Structure for Efficient Numerical Computation. Comput. Sci. Eng. 2011, 13, 22-30.

(31) van der Walt, S.; Schönberger, J. L.; Nunez-Iglesias, J.; Boulogne, F.; Warner, J. D.; Yager, N.; Gouillart, E.; Yu, T. ScikitImage: Image Processing in Python. PeerJ 2014, 2, e453.

(32) Hunter, J. D. Matplotlib: A 2D Graphics Environment. Comput. Sci. Eng. 2007, 9, 90-95.

(33) Oliphant, T. E. Python for Scientific Computing. Comput. Sci. Eng. 2007, 9, 10-20.

(34) Schneider, C. A.; Rasband, W. S.; Eliceiri, K. W. NIH Image to ImageJ: 25 Years of Image Analysis. Nat. Methods 2012, 9, 671-675.

(35) Molla, S.; Eskin, D.; Mostowfi, F. Pressure Drop of Slug Flow in Microchannels with Increasing Void Fraction: Experiment and Modeling. Lab Chip 2011, 11, 1968-1978.

(36) Li, X.; Fan, X.; Brandani, S. Difference in Pore Contact Angle and the Contact Angle Measured on a Flat Surface and in an Open Space. Chem. Eng. Sci. 2014, 117, 137-145.

(37) Siebold, A.; Nardin, M.; Schultz, J.; Walliser, A.; Oppliger, M. Effect of Dynamic Contact Angle on Capillary Rise Phenomena. Colloids Surf., A 2000, 161, 81-87.

(38) Blake, T. D.; Shikhmurzaev, Y. D. Dynamic Wetting by Liquids of Different Viscosity. J. Colloid Interface Sci. 2002, 253, 196-202.

(39) Savva, N.; Kalliadasis, S. Droplet Motion on Inclined Heterogeneous Substrates. J. Fluid Mech. 2013, 725, 462-491. 